Brit. Heart F., 1966, 28, 40.

\title{
Value of Coronary Arteriography in the Investigation of Ischæmic Heart Disease
}

\author{
G. HALE, ^ D. DEXTER, K. JEFFERSON, AND A. LEATHAM† \\ From St. George's Hospital, London S.W.1
}

Coronary arteriography may well contribute to our understanding and ability to diagnose and manage ischæmic heart disease. It is timely therefore to reflect briefly on the progress in our knowledge of this common and deadly malady since the end of the 18th century when the features and the prognosis of angina pectoris were so clearly described by Heberden (Willius and Keys, 1941). For about a hundred and fifty years progress was slow, since there were many different theories concerning the ætiological basis of angina (Huchard, 1890, quoted by Allbutt, 1915), and hence uncertainty in differentiation from other causes of chest pain was inevitable. At the beginning of this century understanding of ischæmic heart disease was greatly improved in two ways; first, by a general appreciation from pathological studies of the importance of obstructive coronary disease in the causation of myocardial infarction, angina, and even sudden death (Herrick, 1912); and secondly, by the introduction of electrocardiography and recognition of the changes observed in myocardial infarction. Correlation between clinical, electrocardiographic, and pathological findings led to greater certainty in the diagnosis of cardiac pain not only because a means of gaining support for the diagnosis in life was available, but also because the new knowledge led to an increased awareness of the distinctive symptom of angina. To recall that Heberden was able to diagnose angina, and to describe it with great clarity, without ancillary aids, and without knowing how to obtain confirmation after death, emphasizes once more the great value of his contribution.

At the present time a compatible history is still

Received May 12, 1965. cil.

* Supported by a grant from the Medical Research Coun-

† A summary of this work was given as the St. Cyres lecture 1963. the first requisite for a diagnosis of cardiac pain, and valuable clues to the severity of myocardial ischæmia in a patient with cardiac pain can be obtained from a careful study of effort tolerance. The place of further laboratory tests in this situation is purely supportive, unless particular information such as localization of coronary narrowing is required for direct coronary surgery. While clinical diagnosis of the cause of chest pain is relatively straightforward in most cases, a proportion remains in whom a satisfactory diagnosis is not obtained and doubt may be most harmful to the patient, while a false diagnosis of coronary disease is a not uncommon cause of unnecessary cardiac invalidism (Evans, 1959). Electrocardiography is then the most useful objective investigation available for assessing myocardial ischæmia, and the finding of $S-T$ depression and $T$ inversion, especially if transient and associated in time with symptoms suggesting myocardial ischæmia, offers valuable confirmatory evidence. Nevertheless electrocardiography has some limitations and $\mathrm{S}-\mathrm{T}$ and $\mathrm{T}$ changes may have an alternative explanation. Thus faults in the machine or in electrode application may give false positive findings, and there are other causes of $S-T$ and $T$ wave changes that may be confused with ischæmia, such as pericarditis, digitalis, following paroxysmal tachycardia, myocarditis, cardiomyopathy, disorders of metabolism, and abnormalities of conduction and ventricular hypertrophy. Negative findings may also be obtained in patients with severe coronary disease causing typical angina pectoris, particularly if tracings are not obtained frequently and within the first few days or weeks of the onset of the symptoms. Uncommonly, even with such care, there may be no electrocardiographic abnormalities.

It is clear that other methods of assessing myocardial ischæmia must be explored, and measure40 
best index; but this is not practicable at present. In the meantime, any method of obtaining objective information about the state of the coronary arteries would be an advance, no matter how limited the application might be at first. Coronary arteriography gives information about the anatomy and severity of obstructive disease (and some indication of flow under resting conditions). Information about localization and extent of occlusive disease would be essential if coronary endarterectomy were to be contemplated. For these reasons, it was decided to investigate the techniques and value of coronary arteriography, initially in animals (Sloman and Jefferson, 1960; Michell and Jefferson, 1962), and later in man (Hale and Jefferson, 1963). Our objectives have been to find a technique for coronary arteriography which is safe and capable of yielding extremely clear pictures, and secondly to correlate these findings with the history, the electrocardiogram, and, when possible, the pathological findings.

\section{SubJeCtS AND Method}

In our investigation we have concentrated on three groups of patients. First, those whose dominant symptom was angina on effort and at rest, and in whom direct coronary arterial surgery had been considered because of the severity of their symptoms; secondly, a group of patients in whom the problem was one of diagnosis; and thirdly, patients with valvular heart disease and angina in whom there was doubt about the advisability of valve surgery.

The technique of selective coronary arteriography was used for reasons which have been described previously (Hale and Jefferson, 1963); it was devised by Sones (1960) because he found that reliable coronary arteriograms could not be obtained by any simpler method. From a smaller experience we reached the same conclusion, and furthermore, even with selective arteriography, demonstration of significant narrowing requires technical perfection. The safety of the technique had been clearly shown by Sones who had performed selective coronary arteriography on more than 600 patients by the end of 1960 with only 2 deaths. This was before the full development of external methods of resuscitation which subsequently helped to revive a number of patients successfully from cardiac arrest. A more recent report from the Cleveland Clinic (F. M. Sones, 1963, personal communication) described his experience in a total of 1500 patients, with only one additional death from the procedure since the earlier report.

We adopted the selective coronary technique in 1960 , and in the subsequent 30 months, 26 patients were investigated without untoward result. The series was small because our indications were rigidly applied and the examination performed only when it was considered that it would materially assist diagnosis or treatment. In all patients clinical assessment included a thorough history and physical examination, electrocardiography, and an "objective as possible" appraisal of exercise tolerance, using a bicycle ergometer and carried to the point of fatigue or angina. While cycling against a standardized and graded increase in resistance, the electrocardiogram (lead CR3 or 4) was monitored and recorded. Before, and for 10 minutes after the effort, limb leads (at least I and VF) as well as the selected V or CR lead were recorded. The CR lead was preferred to the corresponding $\mathrm{V}$ lead because we found less somatic tremor with the CR lead during cycling, and we were interested in the changes during, as well as after, exertion. In addition the bipolar CR lead was thought to be more sensitive than the corresponding $\mathrm{V}$ lead in displaying minor S-T deviations (Evans, 1959).

The interpretation of coronary arteriograms has been discussed elsewhere (Hale and Jefferson, 1963). Here it was suggested from a correlation of arteriographic findings in life, with pathological findings in 4 of the 6 patients who subsequently died, that even a slight irregularity in an arteriogram represented a significant functional lesion. Nevertheless our experience is small and since distinction between anatomical and pathological changes on an arteriogram may not always be certain, a simple classification of obstructive coronary "disease" has been used in assessing and comparing coronary arteriograms and is indicated below in order of severity.

(1) Occlusion of the trunk of one of the three major coronary arteries (anterior descending, circumflex, or right) was graded ++ .

(2) Occlusion of a major arterial trunk distal to the larger branches, or narrowing of a main trunk to one-third or less of the expected diameter, was graded + .

(3) When ++ or + lesions were absent, even when lesser degrees of narrowing by disease were suspected, the arterial tree was regarded as within normal limits and graded 0.

The 26 cases fall into 3 major categories which represented our indications for the procedure.

A. 15 patients with angina pectoris of long duration (usually more than 12 months).

B. 6 patients with chest pain not typically cardiac in origin.

C. 5 patients with angina pectoris and valvular heart disease especially aortic stenosis.

\section{RESULTS}

\section{Findings in Group $A$}

The group of 15 patients with chronic angina was the largest because the chief aim when we began our investigation 6 years ago was to find patients with angina suitable for direct coronary surgery. If direct coronary surgery had a place in the treatment of coronary artery disease, the patients in this group clearly deserved consideration because of their age and the severity of their symptoms. All 
A

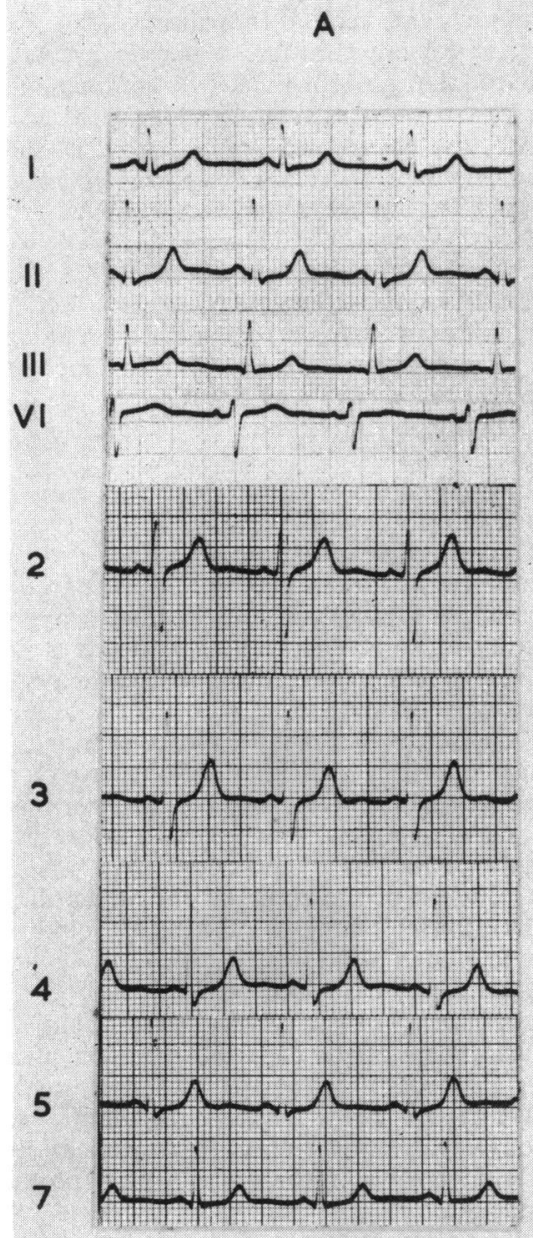

V4 AFTER EXERCISE

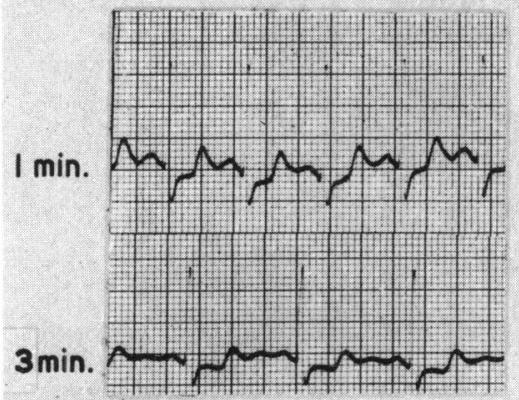

I<smiles>C1CC2CCC2C1</smiles>

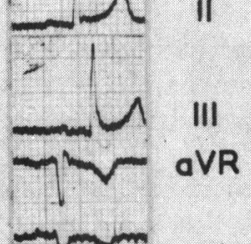

$\sqrt{1 m}$

aVL
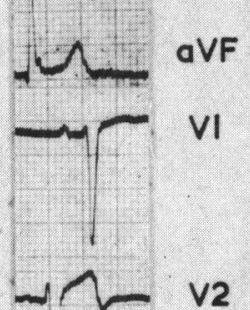

a
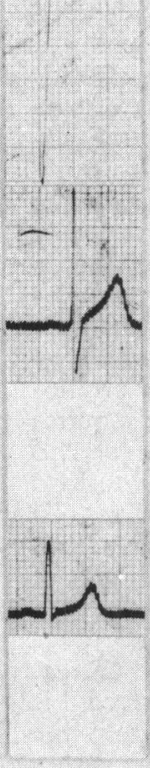

aVF

VI

V2

v3

V4

V5

V7
B
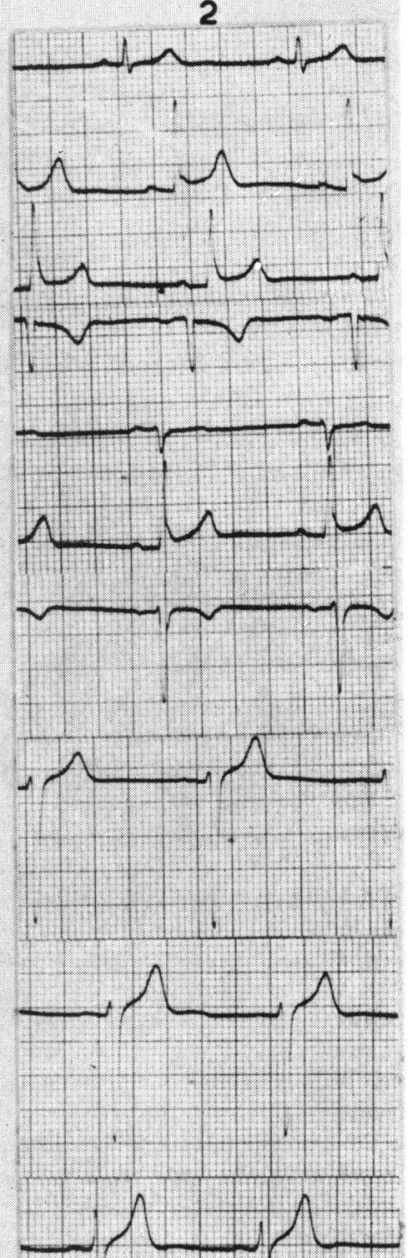

Fig. 1.-(A) Electrocardiogram of a 54-year-old woman (Case 5) with a 2-year history of increasingly severe effort angina and a coronary arteriogram showing multiple and diffuse narrowing of all major coronary arteries. The record is within normal limits at rest but abnormal with exercise.

(B) Electrocardiograms of a 53-year-old man (Case 10) taken at the onset of his pain (1) and during admission for coronary arteriography $2 \frac{1}{2}$ years later (2). Arteriography showed occlusion of the anterior descending coronary artery and moderate narrowing of other branches (Fig. 4, Hale and Jefferson, 1963). Nevertheless only the initial record showed abnormalities (V2), presumably following anterior descending occlusion; exercise test negative. 
but two were male patients, the age range in the whole group was 37 to 58 years with a mean of 47 years, and all had chronic and usually incapacitating angina. The duration of the angina varied from 6 months to 10 years with a mean of $3 \frac{1}{2}$ years. During the period of study, 5 deaths occurred in this group (Cases 1, 6, 9, 11, and 14) and necropsy with detailed study of the coronary arteries was performed in 3 (Cases 6, 9, and 11).

In the electrocardiogram, evidence of old infarction in the form of pathological $Q$ waves was found in 6 patients (Cases 8, 9, 11, 12,14, and 15) though no episodes of clinical infarction were experienced in 3 (Cases 8, 9, 11). In 6 others (Cases 1, 2, 4, 6, 7 , and 13), segmental S-T depression and flat $T$ waves were the only finding. In one (Case 3), only left axis deviation (S2, S3 pattern) was found. In 2 patients the resting electrocardiograms were normal on many occasions; in one (Fig. 1A) abnormalities appeared after effort and six months later S-T depression was noted during prolonged bouts of chest pain: in the other (Fig. 1B), even the electrocardiogram after effort was normal, but the initial tracing taken 6 weeks after the onset of angina had shown a biphasic $\mathrm{T}$ in V2.

At coronary arteriography (Table I), the main finding was one of diffuse and severe coronary narrowing, excluding 2 patients (Cases 2 and 8) about whom insufficient information was obtained. Thus occlusion or severe narrowing was demonstrated in at least 2 of the 3 main coronary arteries in 10 of the remaining 13 patients; it was of interest to find occlusion in 3 (Cases 4, 6, and 10) without a history or electrocardiogram suggesting myocardial infarction.

A 56-year-old accountant (Case 10) had had unchanging angina of effort for $2 \frac{1}{2}$ years. The pain was brought on by walking between 150 and 400 yeards on the level and there were no special or prolonged attacks. When he first sought advice six weeks after the onset of effort pain, the electrocardiogram showed a biphasic $T$ in V2 (Fig. 1B); but two months later, and thereafter, there were no electrocardiographic abnormalities at rest or with effort. Coronary arteriography $2 \frac{1}{2}$ years after the onset of angina showed complete occlusion of the anterior descending artery (see Fig. 4 of Hale and Jefferson, 1963). In both the circumflex and right coronary arteries there were additional focal sites of narrowing, the diameter being reduced in each to approximately one-quarter to one-third.

It is probable that the onset of angina was precipitated by the anterior descending artery occlusion, particularly in view of the anterior chest lead showing terminal $T$ inversion (Fig. 1B). Such an occlusion presumably developed gradually or
TABLE I

RESULTS OF IN VIVO CORONARY ARTERIOGRAPHY IN SEVERE CHRONIC ANGINA OF EFFORT

\begin{tabular}{|c|c|c|c|c|c|c|}
\hline \multicolumn{3}{|c|}{$\begin{array}{l}\text { Case No., sex, } \\
\text { and age }\end{array}$} & $\underset{(\mathrm{yr} .)}{\text { Angina }}$ & Ant. desc. & Left circ. & Right \\
\hline $\begin{array}{r}1 \\
2 \\
3 \\
4 \\
5 \\
6 \\
7 \\
8 \\
9 \\
10 \\
11 \\
12 \\
13 \\
14 \\
15\end{array}$ & $\begin{array}{l}M \\
M \\
M \\
M \\
M \\
F \\
M \\
F \\
M \\
M \\
M \\
M \\
M \\
M \\
M \\
M\end{array}$ & $\begin{array}{l}39 \\
49 \\
39 \\
42 \\
54 \\
50 \\
48 \\
48 \\
51 \\
56 \\
45 \\
52 \\
38 \\
58 \\
37\end{array}$ & $\begin{array}{r}4 \\
5 \\
7 \\
5 \\
2 \\
2 \\
2 \\
4 \\
3 \\
2 \\
4 \\
2 \\
1 \\
10 \\
2\end{array}$ & $\begin{array}{r}0 \\
? \\
+ \\
++ \\
+ \\
++ \\
+ \\
0 \\
+ \\
++ \\
++ \\
+ \\
++ \\
++ \\
++ \\
+\end{array}$ & $\begin{array}{l}0 \\
? \\
+ \\
+ \\
+ \\
+ \\
0 \\
0 \\
+ \\
+ \\
+ \\
+ \\
+ \\
+ \\
0\end{array}$ & $\begin{array}{r}0 \\
+ \\
+ \\
++ \\
+ \\
0 \\
0 \\
? \\
+ \\
+ \\
++ \\
+ \\
+ \\
+ \\
0\end{array}$ \\
\hline
\end{tabular}

Degree of obstruction: Complete ++ ; moderate or severe + .

intermittently since it is unlikely that a sudden complete occlusion in an artery not greatly narrowed by disease could have occurred without causing more dramatic symptoms. This patient with severe disease of all 3 major vessels demonstrates the usual findings in severe chronic angina; nevertheless he was no worse 3 years later.

The state of the main artery and branches distal to an occlusion, or to severe segmental narrowing, was examined. The site of occlusion or narrowing of the main vessels in the coronary arteriograms began invariably within the first 4 to $5 \mathrm{~cm}$. in both left and right vessels as expected (Schlesinger and Zoll, 1941). Coronary endarterectomy would be technically possible in these proximal segments, though not in the more distal segments and branches, but relief of proximal with continuing distal occlusion might not be worth while. Detailed examination of the distal arterial tree was therefore essential, and our findings distal to an occlusion in the first $5 \mathrm{~cm}$. of a main coronary artery are presented in Table II. Only 2 of the 11 arteries were shown to be free of narrowing beyond the occlusion. The artery in both patients (Cases 13 and 14) was the posterior interventricular branch of the right coronary artery. In Case 13, this branch was filled not only from its parent right coronary artery, but also from the two patent divisions of the left coronary artery, despite the fact that not one of the collateral vessels directly supplying the posterior interventricular artery from the left coronary artery was outlined by cine-angiography (Fig. 2). From the ease with which patent distal branches were outlined we drew the conclusion that absence of distal filling with the cannulation technique usually indicated occlusion of distal branches. Indeed, of the 4 patients in whom arteriography had shown no 
TABLE II

ARTERIOGRAPHIC FINDINGS IN CORONARY ARTERIES WITH PROXIMAL OCCLUSIONS

(11 arteries from 8 patients)

\begin{tabular}{|c|c|}
\hline & No. of arteries \\
\hline $\begin{array}{l}\text { Intact lumen in artery distal to a long }(5-6 \mathrm{~cm} .) \\
\text { occlusion } \\
\text { Severe narrowing of main artery distal to occlu- } \\
\text { sion (possibly recanalization ?) } \\
\begin{array}{l}\text { Only collateral or distal branches outlined } \\
\text { No opacification distal to occlusion }\end{array}\end{array}$ & $\begin{array}{l}2 \\
4 \\
1 \\
4\end{array}$ \\
\hline & 11 \\
\hline
\end{tabular}

$\star$ Three of the 4 patients in this group came to necropsy and severe occlusive disease of the distal trunk was demonstrated in all 3.

opacification distal to occlusion of a major coronary artery (Table II, group 4), 3 came to necropsy, and serial sections showed severe and diffuse atheroma extending distally from the proximal block (see Case 11 discussed later). It must be admitted, however, that in some cases, unexplained failure to form collateral channels might be a factor in preventing patent distal branches from filling. Nevertheless, absence of collateral channels in our experience was seen only in those patients with occlusive disease of both main coronary arteries in their proximal and distal segments including their major branches. In Case 4 the distal branches of the right coronary artery (group 3, Table II) showed well-marked filling due to collateral channels forming from at least three spared branches proximal to the occlusion.

The extent of narrowing or obliteration of the lumen distal to severe proximal narrowing (" + " on our arbitrary classification) was also reviewed. Nineteen arteries (in 11 patients) had a proximal stenosis ("+"), and in 15 of them diffuse and irregular narrowing was observed distally. Only in 4 arteries was there no evidence of distal narrowing on the arteriogram, and in one of them (Case 11, anterior descending artery) necropsy revealed diffuse atheromatous narrowing.

Clearly our experience, though limited, confirms the findings of pathologists at necropsy, that in the presence of detectable severe narrowing in the proximal segments of a main coronary artery, diffuse distal disease is the rule rather than the exception.

In the first half of our investigation we had not appreciated the reliability of selective arteriography in outlining branches distal to obstruction, if still patent, and it was thought that failure to fill might
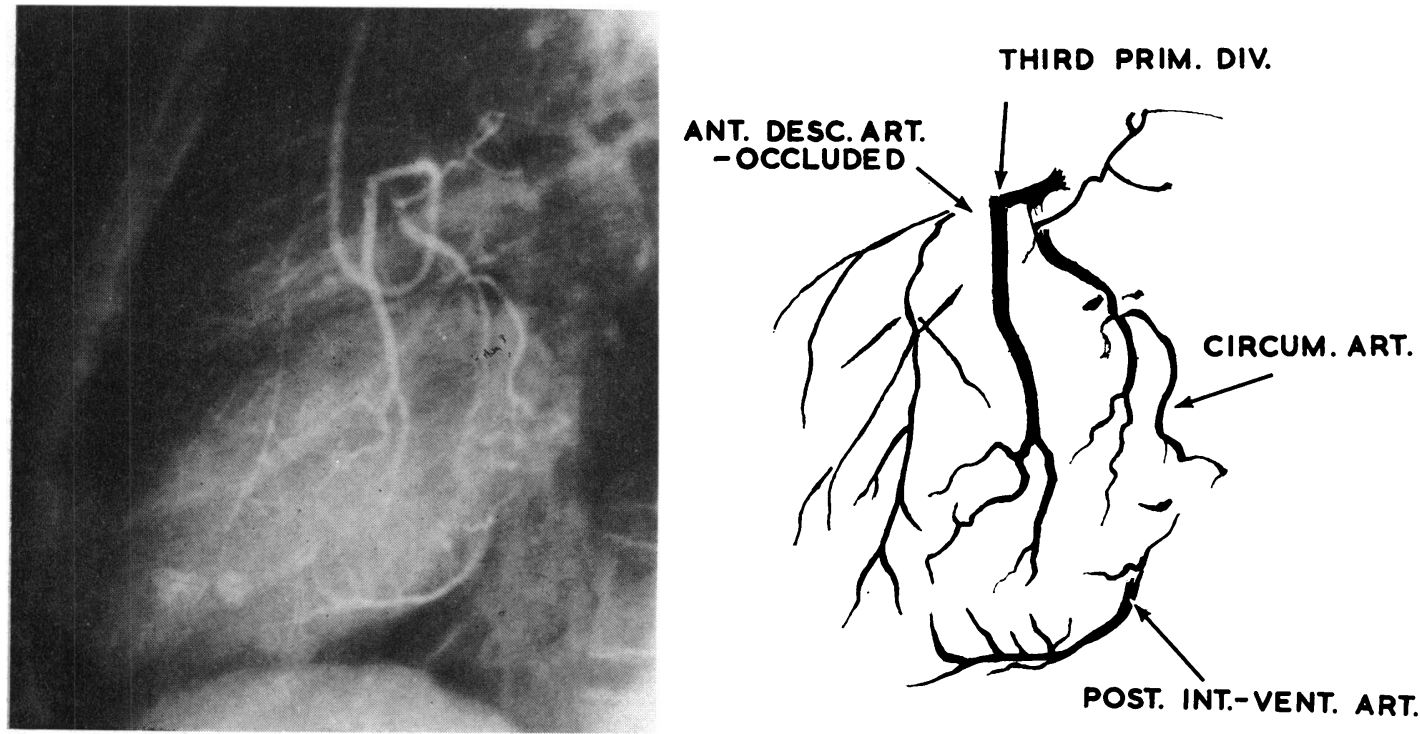

FIG. 2.-Coronary arteriogram (single film in the left lateral position) of a 37-year-old man (Case 13) with a history of effort angina for 12 months, and an anterior myocardial infarction two years earlier. The posterior interventricular artery was filled during a left coronary arteriogram even though the collateral branches were too small to be outlined by arteriography. It was concluded from this and other cases that the opaque medium would penetrate to any patent vessel in chronic angina and that absence of filling peripheral to a block usually indicated absence of peripheral lumen. Note also the occlusion of the anterior descending artery just distal to the origin of the large first major branch of this artery (so-called third primary division) fitting in with the electrocardiographic diagnosis of anterior infarction. 
be due to absent or delayed collateral flow or excessive dilution of contrast medium. Case 11 illustrates the importance of making a close study of the arterial tree distal to an occluded coronary artery, particularly when direct coronary artery surgery is contemplated.

A 45-year-old clerk (Case 11) presented with increasing angina for four years. Because of the severity of his pain - with attacks at rest as well as with mild efforthe had been unable to work during the 12 months before investigation. Although there had been no obvious clinical episodes of myocardial infarction his electrocardiogram showed abnormal $Q$ waves in lead V4. He had bilateral xanthelasma palpebrum and a raised plasma cholesterol $(350 \mathrm{mg} . / 100 \mathrm{ml}$.). The blood pressure was always normal. Coronary arteriography (August 1961) demonstrated a complete right coronary artery occlusion and narrowing to at least one-third the original diameter of both anterior descending and circumflex arteries (Fig. 3). The posterior interventricular artery was not outlined at any stage; two findings suggested that it was a branch of the right coronary artery (and therefore the "dominant" artery), namely, the large diameter of the outline of the first $2 \mathrm{~cm}$. of the right coronary artery, and the absence of any indication of a large posterior interventricular branch of the left coronary artery.

At operation (November 1961), using biventricular bypass and hypothermia (to a nasopharyngeal temperature of $25^{\circ} \mathrm{C}$.), a $6 \mathrm{~cm}$. plug of "atheromatous" tissue was removed from the right coronary artery with apparent improvement in both forward and retrograde flow. He was taken off bypass successfully, but developed irreversible ventricular fibrillation after he had recovered consciousness. All attempts at resuscitation failed.

Necropsy showed the presence of extensive coronary atherosclerosis and of old scarring in the lateral left ventricular wall. Coronary arteriograms were performed using a technique described previously (Crawford, Dexter, and Teare, 1961). As expected, the two branches of the left coronary artery were severely narrowed near their origin, but the degree of narrowing was perhaps greater than that predicted from arteriography three months before death. Histology showed (Fig. 3) complete obliteration of the lumen of the posterior interventricular branch of the right coronary artery by atheroma beyond the distal end of the cleared segment of this artery. The thromboendarterectomy specimen included most of the medial coat which was unrecognizable as such because of mural fibrosis. As a result it can be seen that the wall of the right coronary artery left in situ consisted only of adventitia and a thin layer of fibrous tissue coated by flecks of fibrin. Near the orifices of the right coronary artery, and proximal to the endarterectomized segment, there was a mural thrombus which was considered, on histological grounds, to have formed at some time between arteriography and operation. At operation this narrowing did not prevent a good flow through the arteriotomy site, and its existence was unsuspected and might have been an important factor limiting improvement if the "run-off" had been adequate. Representative frames from the cine film of left and right coronary arteriograms, tracings of post-mortem coronary arteriograms, and sections of the coronary arteries at the levels indicated are shown in Fig. 3.

The severity of coronary disease in this patient corresponded well with the severity of his symptoms though the extent of coronary narrowing and obliteration at necropsy was if anything greater than expected. Thus it had been hoped that failure to outline distal branches of the right coronary artery had been due to technical factors, whereas the real reason had been extensive atheromatous obliteration of the lumen extending well into posterior interventricular artery, preventing run-off beyond a satisfactory endarterectomy (Fig. 3). Failure to achieve the almost impossible task of removing all the obliterative material in the right coronary artery and the severity of disease elsewhere in the coronary arterial tree were responsible for his death.

Little or no coronary disease was found in 3 patients (Cases 1, 7, and 15) with classical angina pectoris of 2 to 4 years' duration. All 3 had abnormal resting electrocardiograms, including widespread $Q$ waves in the chest leads in one (Case 15).

A car dealer (Case 15, aged 37 years) has been discussed elsewhere (Hale and Jefferson, 1963). He presented 2 years before investigation with a severe and prolonged episode of chest pain preceded by 2 weeks of effort pain in the left arm which was interpreted as pre-infarction angina. Infarction was confirmed by the electrocardiogram ( $Q$ waves and $S-T$ elevation in leads C2 to V5) and a raised SGOT (90 units). Recovery was slow, and angina-severe and unchanging-prevented resumption of work. Arteriography showed a spiral-shaped narrowing of the anterior descending artery near its origin (Fig. 6 of Hale and Jefferson, 1963), presumably the site of thrombosis precipitating myocardial infarction 2 years before. Slight narrowing in the circumflex artery and focal irregularity of outline without definite narrowing in the dominant right coronary artery were the other findings.

The coronary arteriogram in Case 15 was at first regarded as normal, for the presence of a severe anterior descending artery stenosis was not detected until the terminal clearing phase of several arteriograms was carefully examined. It is concluded that some sites of coronary narrowing may be overlooked unless care is exercised, particularly after recanalization of a thrombus, as was likely in this patient and will be discussed later.

The other patients (Cases 1 and 7) differ in that no lesion was observed in any part of the coronary tree. 


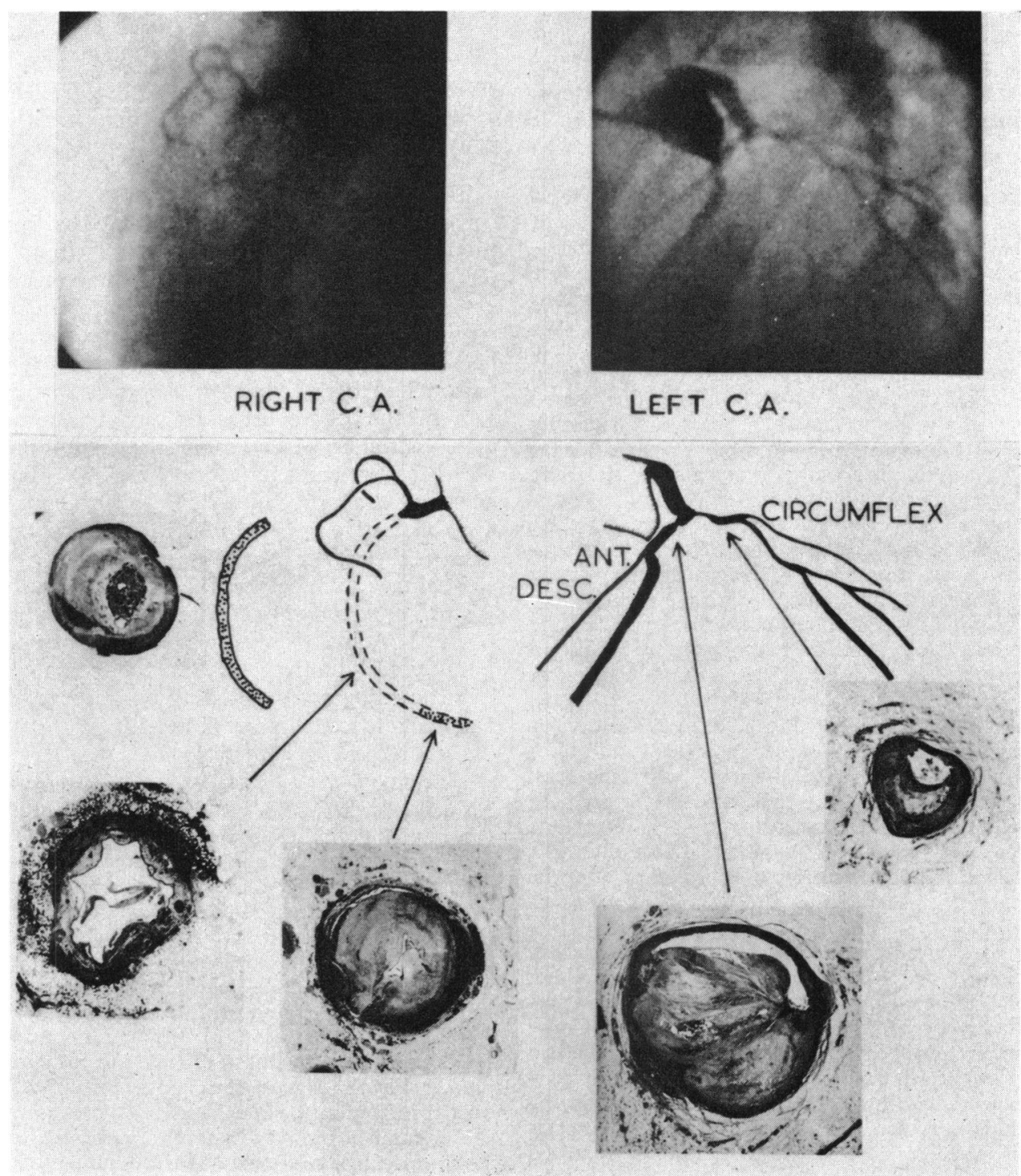

Fig. 3.-Coronary arteriograms (left anterior oblique) in a man aged 45 (Case 11) with incapacitating angina for four years, made three months before death, showing completely occluded right coronary artery (Right C.A.) and severe narrowing of anterior descending and circumflex (Left C.A.). Below the relevant arteriogram are shown drawings of the post-mortem injections with photomicrographs of the sections at levels which are indicated. The significance of the lack of filling of the distal part of the right coronary artery had not been realized and its complete obstruction (see section) must have prevented run-off from the successfully cleared proximal portion (dotted line).

A bus conductor (Case 1, aged 39 years) came in August 1960 with a 4 years' history of angina of effort and 2 episodes of prolonged chest pain, associated on the second occasion with electrocardiographic signs of anterior myocardial infarction. Arteriography showed possible slight irregularity, but no narrowing, of the dominant right coronary artery, and no narrowing of either branch of the left coronary artery. Six months after the study he died suddenly while waiting in a bus queue. Necropsy was unfortunately not performed presumably because of the strong clinical suspicion of ischæmic heart disease.

A housewife (Case 7, aged 48 years) gave a 4-year history of typical angina pectoris and 3 episodes, each lasting several weeks, of prolonged attacks of pain at 
rest. Arteriography was performed several weeks after subsidence of the last period of rest pain. Electrocardiography at the time of investigation showed $\mathrm{T}$ inversion in leads I, III, and V3 to V7. She was still menstruating and had a normal blood pressure, but there was a strong family history of hypertensive vascular disease. There were no clinical features to suggest a diagnosis other than coronary atherosclerosis. Coronary arteriography (June 1961) showed a normal dominant left coronary artery and a diminutive, though normal, right coronary artery. Subsequently her angina regressed, but 8 years after the onset of symptoms she was still limited to light housework.

These cases are at present poorly understood. It is possible that they have coronary atherosclerosis with only minimal disease of distal branches not outlined by arteriography (illustrated by Case 23, Fig. 5). It is of interest that 2 of these patients (Cases 7 and 15) are doing well 4 years after arteriography; but further follow-up and perhaps coronary arteriograms will be necessary to elucidate this problem.

\section{Findings in Group $B$}

During a period of 2 years, 6 patients with the diagnostic problem of chest pain suggestive, but not typical, of a cardiac origin were investigated because of the severity of the symptom and the need to reach a precise diagnosis. Although the pain resembled angina in all patients, the relation of the pain to effort was usually poor, and the electrocardiogram at rest and with effort was normal in 4 patients and showed only non-specific abnormalities in another (Case 21). In the remaining patient (Case 20) $Q$ waves in the anterior chest leads fitted in with a history of old myocardial infarction, but he had made a good recovery and the incapacitating pain at the time of our investigation was quite unlike cardiac pain. These cases are summarized in Table III.

As a result of our experiences in patients with severe chronic angina (group A, Table I) and in pathological studies (Dexter, 1964), we worked on the hypothesis that narrowing of 2 or 3 main coronary branches was likely to be associated with ischæmic cardiac pain. If only one branch was diseased (usually anterior descending) it was thought impossible to decide, on arteriography alone, whether the pain was due to cardiac ischæmia, but the findings of arteriography combined with the history, clinical examination, and electrocardiogram usually helped us to come to a conclusion. It will be seen that of the group of patients with undiagnosed chest pain (Table III), most had involvement of one major vessel, but we were able to come to a definite diagnosis in 5 of the 6 patients, substantiated by follow-up three years later.

A salesman (Case 21, aged 46 years) gave a 6 -month history of attacks of chest pain not related to effort. The severity, duration, and site of his first attack of pain strongly suggested acute coronary thrombosis, but repeated electrocardiograms failed to show certain evidence of ischæmia. Thus slight flattening of the $T$ wave in leads I and V5 in one trace, and slight S-T depression in V4 in another, were not considered sufficient to diagnose cardiac pain. Coronary arteriography showed obstruction of the anterior descending artery at a point of origin of a main septal branch best shown in the left anterior oblique view (Fig. 4, note the need for more than one plane). The arteriographic finding of an anterior descending artery occlusion offered such a convincing explanation for both the attacks of pain and the equivocal and variable anterior electrocardiographic changes, that the diagnosis of cardiac pain was inescapable. Three years later the pain had disappeared as would be expected with disease localized to one vessel, and his electrocardiogram had returned to normal.

A single woman (Case 17, aged 62 years) presented with an 18-month history of severe constricting central chest pain, usually, but not always, induced by effort. Two features not characteristic of angina were, first, the long duration (20-30 min.), and secondly, the occasional attack of pain that followed relatively minor exertion involving work with out-stretched arms. Electrocardiograms at rest and with effort were normal.

TABLE III

CORONARY ARTERIES IN PATIENTS WITH UNDIAGNOSED CHEST PAIN

\begin{tabular}{|c|c|c|c|c|c|c|c|}
\hline \multicolumn{3}{|c|}{$\begin{array}{l}\text { Case No., sex, } \\
\text { and age }\end{array}$} & \multirow[t]{2}{*}{ History } & \multicolumn{3}{|c|}{$\begin{array}{l}\text { Degree of coronary obstruction } \\
\text { from arteriography }\end{array}$} & \multirow{2}{*}{$\begin{array}{l}\text { Final } \\
\text { conclusion }\end{array}$} \\
\hline & & & & Ant. desc. art. & Circum. & Rt. cor. art. & \\
\hline $\begin{array}{l}16 \\
17\end{array}$ & F & $\begin{array}{l}38 \\
62\end{array}$ & \multirow{2}{*}{$\begin{array}{l}2 \text { yr. high chest pain with rest and effort } \\
2 \text { yr. attacks of severe chest pain with rest } \\
\text { and effort } \\
1 \text { yr. attacks of pain at rest } \\
1 \text { yr. attacks of pain at rest } \\
3 \text { yr. chest pain; } 2 \text { attacks proven infarction } \\
6 \text { months of attacks of chest pain at rest }\end{array}$} & $\begin{array}{l}0 \\
+\end{array}$ & $\begin{array}{l}\mathbf{0} \\
0\end{array}$ & $\begin{array}{l}\mathbf{0} \\
\mathbf{0}\end{array}$ & \multirow{2}{*}{$\begin{array}{l}\text { Non cardiac } \\
\text { Non cardiac } \\
\text { Cardiac } \\
\text { Non cardiac } \\
\text { ? Non cardiac } \\
\text { Cardiac }\end{array}$} \\
\hline $\begin{array}{l}18 \\
19 \\
20 \\
21\end{array}$ & $\begin{array}{l}\mathbf{M} \\
\mathbf{M} \\
\mathbf{M} \\
\mathbf{M}\end{array}$ & $\begin{array}{l}52 \\
50 \\
40 \\
46\end{array}$ & & $\begin{array}{l}+ \\
+ \\
+ \\
+\end{array}$ & $\begin{array}{l}0 \\
0 \\
+ \\
0\end{array}$ & $\begin{array}{l}? \\
0 \\
0 \\
0\end{array}$ & \\
\hline
\end{tabular}



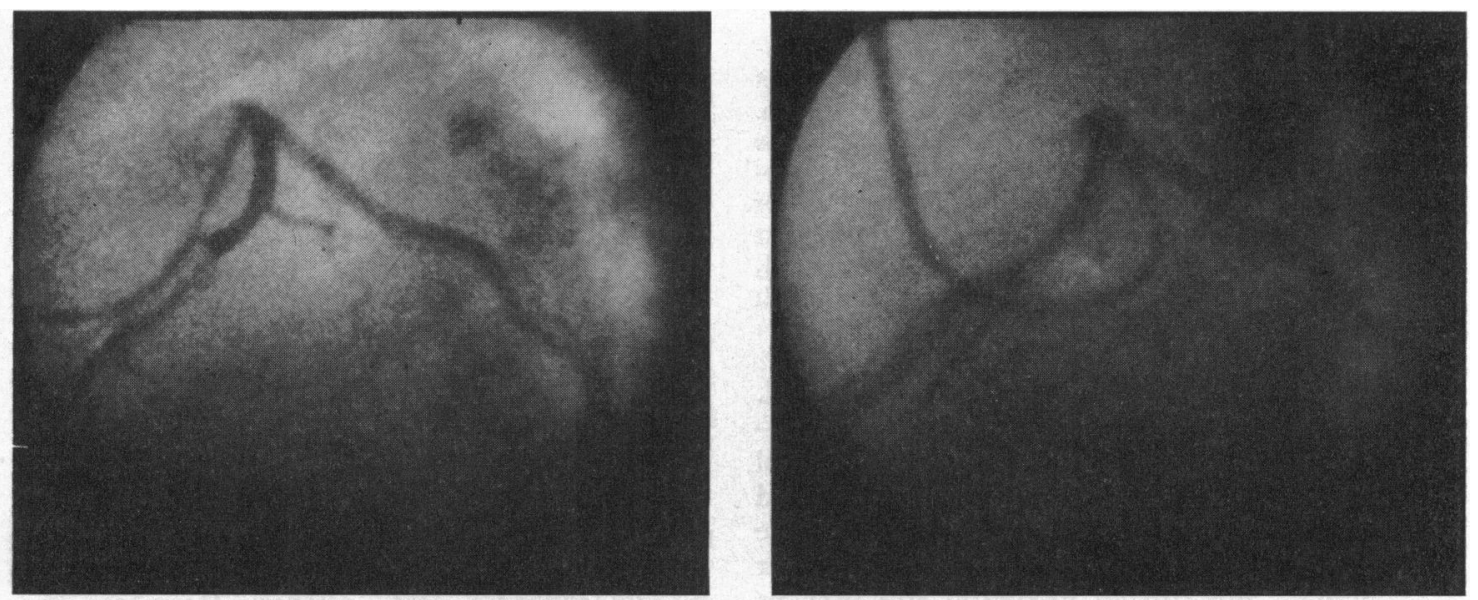

Fig. 4.-Left coronary arteriogram (Case 21) filmed in two planes to show an anterior descending occlusion convincingly demonstrated in one projection (left anterior oblique), but poorly in another (left lateral).

Disease of the cervical spine was suspected clinically and some spondylitic changes were noted radiologically, but cervical spondylosis was considered unlikely to be the cause of pain which was episodic and so severe.

Coronary arteriography showed calcification and slight narrowing of the anterior descending artery, but the remaining arteries appeared to be free of disease. Because these findings suggested that coronary artery disease was not the cause of her severe symptoms, attention was redirected to the neck and led to a trial application of an immobilizing collar. It was probably no coincidence that the attacks of pain greatly lessened, and three years later she was well, though suffering from an obsessional neurosis.

It should be stressed that even a normal coronary arteriogram is occasionally found in patients with undoubted ischæmic cardiac pain (Cases 1 and 7, Table I), and this unexpected finding is discussed later.

\section{Findings in Group C}

In 5 patients with angina pectoris and valvular heart disease (aortic stenosis in Cases 22, 23, 24, and 26, mitral stenosis in Case 25) the purpose of coronary arteriography was to help assess the contribution of coronary disease to the anginal pain, and secondly to help decide if the degree of coronary disease contraindicated valve surgery.

The electrocardiogram never showed $Q$ waves or other undoubted signs of myocardial infarction or ischæmia. In Case 23 (described below) resting and exercise traces were normal. The changes in the others consisted only of non-specific $S-T$ and $T$ abnormalities.
At coronary arteriography severe coronary disease was demonstrated in 4 of the 5 patients (Table IV) and, in the light of our experience in group A, may well have been the sole cause of the angina; in all 4, investigation of the valve lesion at the time of coronary arteriography showed mild stenosis only (aortic valve in Cases 22, 23, and 24, mitral valve in Case 25), giving further evidence that coronary disease was the dominant lesion.

A naval officer (Case 23, aged 42 years) had a 6-month history of mild effort angina. His first attack was experienced while swimming and subsequently angina was induced only by severe effort. He had signs of aortic stenosis and regurgitation, and on clinical grounds the degree of stenosis was judged to be mild. Thus the pulses were not slow rising and the left ventricle felt only slightly hypertrophied. The electrocardiogram was normal at rest and after exercise. The second sound split normally with inspiration, and there was no clinical evidence of pulmonary hypertension. Chest radiograph showed a normal-sized heart shadow, slightly dilated ascending aorta, and normal lung fields.

Cine-aortography showed calcification and immobility of most of the aortic valve and moderate regurgitation. Coronary arteriography revealed a shared coronary pattern with sites of narrowing (to at least one-third of original diameter) in the anterior descending and right coronary arteries. Although there was a gradient of 55 $\mathrm{mm}$. $\mathrm{Hg}$ across the aortic valve, and the pressures in pulmonary artery, wedge pulmonary capillary, and left ventricular diastolic pressures were slightly raised, there did not appear to be sufficient indications for valve surgery at the time, particularly in view of the extent of coronary narrowing found by arteriography.

A month after the investigation he suddenly became 
TABLE IV

CORONARY ARTERY DISEASE IN PATIENTS WITH VALVULAR HEART DISEASE AND ANGINA

\begin{tabular}{|c|c|c|c|c|c|c|c|}
\hline \multirow{2}{*}{\multicolumn{3}{|c|}{$\begin{array}{l}\text { Case No., sex, } \\
\text { and age }\end{array}$}} & \multirow[b]{3}{*}{2 years of anginal pain, ? mild A.S. } & \multirow{2}{*}{\multicolumn{3}{|c|}{$\begin{array}{l}\text { Degree of coronary obstruction } \\
\text { from arteriography }\end{array}$}} & \multirow[t]{2}{*}{ Final conclusion } \\
\hline & & & & & & & \\
\hline 22 & $\mathbf{M}$ & 48 & & $\frac{\text { Ant. desc. }}{+}$ & $\frac{\text { Circum. }}{+}$ & $\frac{\text { Rt. cor. art. }}{+}$ & Cor. disease, mild aortic stenosis- \\
\hline 23 & $\mathbf{M}$ & 42 & 6 months of anginal pain with sud- & + & + & + & Severe coronary disease-no valve \\
\hline 24 & $\mathbf{M}$ & 37 & $\begin{array}{l}10 \text { months of anginal pain and } \\
\text { "rest pain" fluctuating inten- } \\
\text { sity, mild A.S. }\end{array}$ & + & + & 0 & $\begin{array}{l}\text { Severe coronary disease, minimal } \\
\text { aortic stenosis }\end{array}$ \\
\hline 25 & $\mathbf{F}$ & 54 & $\begin{array}{l}8 \text { years of anginal pain and attacks } \\
\text { of "rest pain", mild M.S. }\end{array}$ & ++ & 0 & 0 & $\begin{array}{l}\text { Mild M.S.; coronary occlusion; no } \\
\text { improvement following valvo- }\end{array}$ \\
\hline 26 & $\mathbf{M}$ & 49 & $\begin{array}{l}1 \text { year of anginal pain } 3 \text { mth. } \\
\text { crescendo increase, ? severe } \\
\text { A.S. }\end{array}$ & 0 & 0 & $\mathbf{0}$ & Aortic stenosis requiring surgery \\
\hline
\end{tabular}

Degree of obstruction: complete ++ ; moderate or severe + .

semicomatose and died several hours later. At necropsy the fatal lesion was thought to have been a pontine hæmorrhage with necrosis; there were no signs of bacterial endocarditis, nor any obvious source of emboli. Examination of the heart showed a calcified bicuspid valve with an eccentric opening 1.0 to $1.5 \mathrm{sq}$. $\mathrm{cm}$. in maximum area. The other valves were normal. There was moderate left ventricular hypertrophy without scarring or infarction, and the main coronary arteries showed severe and generalized atheroma with focal narrowing which had been accurately predicted by coronary arteriography in life. A paucity of septal branches had been noticed and an almost occluded branch suspected during examination of the cine film because a transient streak of opaque medium was observed close to the anterior descending artery. At necropsy there was severe disease of major vessels and occlusion of the origin of major branches of the anterior descending which had only been suspected at arteriography (both in vivo and post mortem) because of the streaks near the anterior descending (arrowed in Fig. 5).

The coronary arteriograms in this patient (Case 23) were of great value in demonstrating a serious degree of coronary disease despite the absence of other evidence including electrocardiographic. On the other hand, the extent of disease in the branches of the anterior descending artery was not accurately predicted because of obliteration by atheroma near their origins, though it had been suspected (Fig. 5).

In the fifth patient the normal arteriograms helped to confirm that coronary disease was not a factor in his angina and that valve surgery was indicated.

A 49-year-old clerk (Case 26) presented with a sixmonth history of angina which had rapidly become worse, resulting in attacks of chest pain at rest. The rapid progression of the pain suggested acute coronary insufficiency from coronary disease but, unlike the others in this group, the history and signs were those of severe aortic stenosis. Thus, he had complained of effort breathlessness for 12 years, and the physical and electrocardiographic findings were those of severe left ventricular hypertrophy. Left heart catheterization showed severe aortic stenosis (L.V. pressure $200 / 5$, aorta $100 / 50$ $\mathrm{mm}$. $\mathrm{Hg}$ on withdrawal of a catheter from L.V. to aorta). At the same time coronary arteriography showed normal coronary arteries.

He died suddenly while awaiting valvotomy and the absence of coronary disease was confirmed at necropsy.

\section{Discussion}

State of Coronary Arteries in Patients with Chronic Angina due to Ischarmic Heart Disease, and Prospects of Coronary Endarterectomy. Before examining the findings at coronary arteriography in life in patients with severe angina, it is important to consider the findings at necropsy. Several reports (Zoll, Wessler, and Blumgart, 1951; Szilagyi, McDonald, and France, 1958; Swedlund, Achor, and Edwards, 1962) emphasize the severity of occlusive coronary disease in patients with angina dying from ischæmic heart disease, though Zoll et al. (1951) pointed out that the correlation between the presence and absence of angina, and the degree of coronary narrowing at necropsy, was by no means precise. Post-mortem studies, however, have their limitations, and in assessing the severity of coronary disease one of the factors which must be remembered is arterial contraction after death (Shipley and Gregg, 1944; Duguid and Robertson, 1957). This was clearly demonstrated to us by observations on the right coronary artery in Case 11 during operation for coronary thromboendarterectomy and subsequently at necropsy. While such factors may be expected to influence assessment of partially obstructive lesions caused 


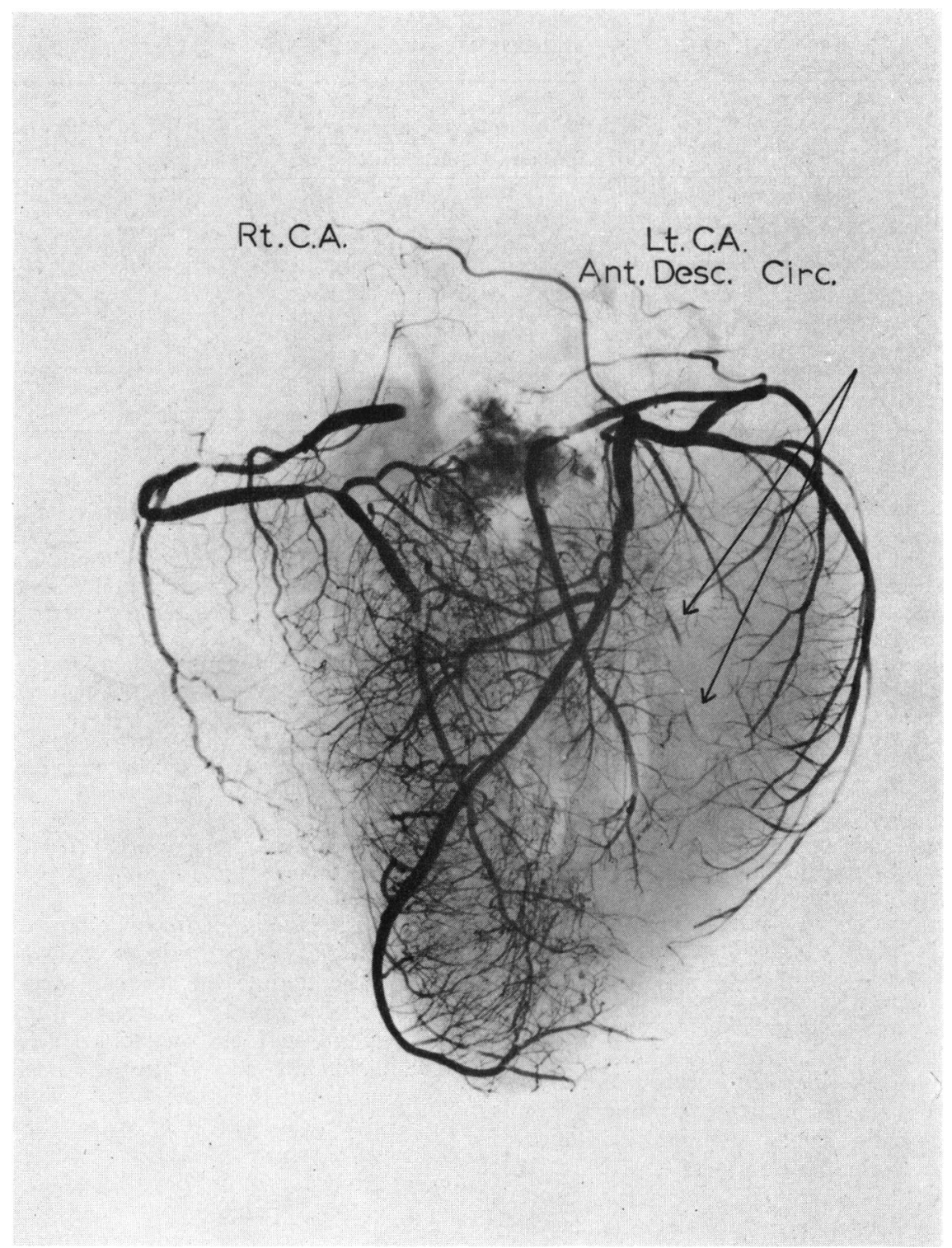

FIG. 5.-Post-mortem arteriogram of Case 23 with combined coronary disease and aortic stenosis. Although the severe disease of the major vessels was clearly shown in both the pre- and post-mortem arteriograms, complete obliteration of major branches of the anterior descending could not be shown by these techniques, though the finding of two linear streaks (arrows) was a clue to the obliteration of two vessels in this case. In other cases there might be no such clue to complete obliteration, and this problem is made even more difficult by the great variation in anatomy of major branches.

by eccentric plaques, they cannot alter the importance of such findings as occlusions or stenotic lesions caused by circumferential rigid thickening.

Reports on the extent of coronary disease found by arteriography in life are few, but it is of interest that one of the earliest (Thal et al., 1958) concluded that the severity of occlusive disease in patients with angina was so great that direct coronary surgery was impracticable. The findings in our patients with long-standing and severe angina agree in general with this conclusion. Major arterial occlusions, even in the absence of clinical infarction, were 
frequently found, and it was usual to find two of the three major arterial trunks severely narrowed. Examination of the arterial tree distal to proximal occlusions also supported the pathologist's claim that coronary disease causing longstanding angina was diffuse and not localized in extent (Table II).

Thus complete proximal obstruction of a major vessel, with endarterectomy technically feasible and tempting because the vessel cannot be made worse, is usually associated with obliteration of distal lumen so that even successful surgery cannot lead to adequate "run-off". Partial proximal obstruction may be associated with good run-off and indeed in Case 10 improvement of the lumen would be likely to do good, but if the patient has sufficiently severe chronic angina for operation to be contemplated, the other major vessels will almost certainly be grossly narrowed, and technical failure or thrombosis of the endarterectomized segment would be disastrous. Furthermore many patients with chronic angina do quite well with conservative treatment (e.g. Case 10), and of our 10 cases with severe diffuse disease only 2 have died up to now ( 3 years later) while 2 died at operation.

On these findings direct arterial surgery would not be expected to have a place in the management of severe chronic angina. Early reports (Cannon, Longmire, and Kattus, 1959; Longmire, Cannon, and Kattus, 1959) demonstrated the possibility of thromboendarterectomy, but their immediate results were discouraging. Sabiston (quoted by Allison, 1962) had an improved operative mortality -5 of 6 patients survived surgery-but re-occlusion of the artery, cleared at operation, was found at subsequent coronary arteriography (R. Ross, 1962, personal communication). Allison (1962) reported 4 operative deaths in 6 patients, while both patients operated on from the present series (Cases 5 and 11) died immediately after operation. The death of these 2 patients and the 4 in Allison's series was clearly the result of severe occlusive disease despite some relief from a disobliterative procedure. It is probable that coronary surgery is not feasible even in patients less severely disabled by angina, and it is salutary to remember in this respect that Szilagyi et al. (1958) found in their necropsy investigation that the only patients with localized disease suitable for endarterectomy had been free of symptoms during life. Nevertheless it should be remembered that these adverse conclusions are based on small numbers of patients studied.

Unexpected Finding of Little or No Disease in Patients with Classical Angina of Long Duration. Three patients (Cases 1, 7, and 15) with undoubted angina pectoris and ischæmic changes on electrocardiography were found to have little or no coronary disease by arteriography. One explanation may be that the method is too insensitive, in that severe narrowing causing significant ischæmia may occasionally be overlooked even with a satisfactory technique employing multiple projections during individual injections of each artery. How often this problem may arise cannot yet be estimated, but some experiences already mentioned suggest that false negative results occur-at least in individual arteries. Furthermore, arteriography cannot hope to display long segments of uniform narrowing in major arteries, nor complete obliteration of major branches (Fig. 5), since there is such great variation in site, size, and distribution of the branches. Finally there may be causes of angina that are at present unknown or unsuspected, and it is even possible that in some of these patients recanalization of a vessel (Case 15) has resulted in an apparently normal arteriogram and perhaps adequate coronary flow, and yet the restriction persists because of fear or other non cardiac mechanisms.

Possible Pathological Basis for Onset and Improvement in Angina, and for Attacks of Angina at Rest. While it is impossible to be certain about the exact sequence of events taking place over a period of years in the coronary arteries of the patients studied, careful analysis of the history, serial electrocardiograms, coronary arteriograms, and finally in some patients pathological examination, may yield information about the mechanisms and natural history of ischæmic heart disease. Our findings clearly indicate that the transient electrocardiographic abnormalities, associated with the onset of angina of effort or worsening of angina, can arise from major arterial-or perhaps major branch thrombosis. As Wood pointed out (1961) in discussing the onset of "acute coronary insufficiency": "It is difficult to believe that anything short of coronary thrombosis could so impoverish the coronary circulation so suddenly." The natural history of some cases of ischæmic heart disease without frank infarction is one of recurring episodes of rest pain, or of sudden worsening of angina. In most cases improvement is the rule, and presumably results from lessening of myocardial ischæmia from increased blood flow through collateral arteries. Perhaps recanalization and retraction of the occluding thrombi may be equally, or more, important. The degree to which experimental thrombi may retract has been well shown by Hand and Chandler (1962), and it is almost certain that the anterior descending arterial stenosis in Case 15 (Fig. 6 of Hale and Jefferson, 


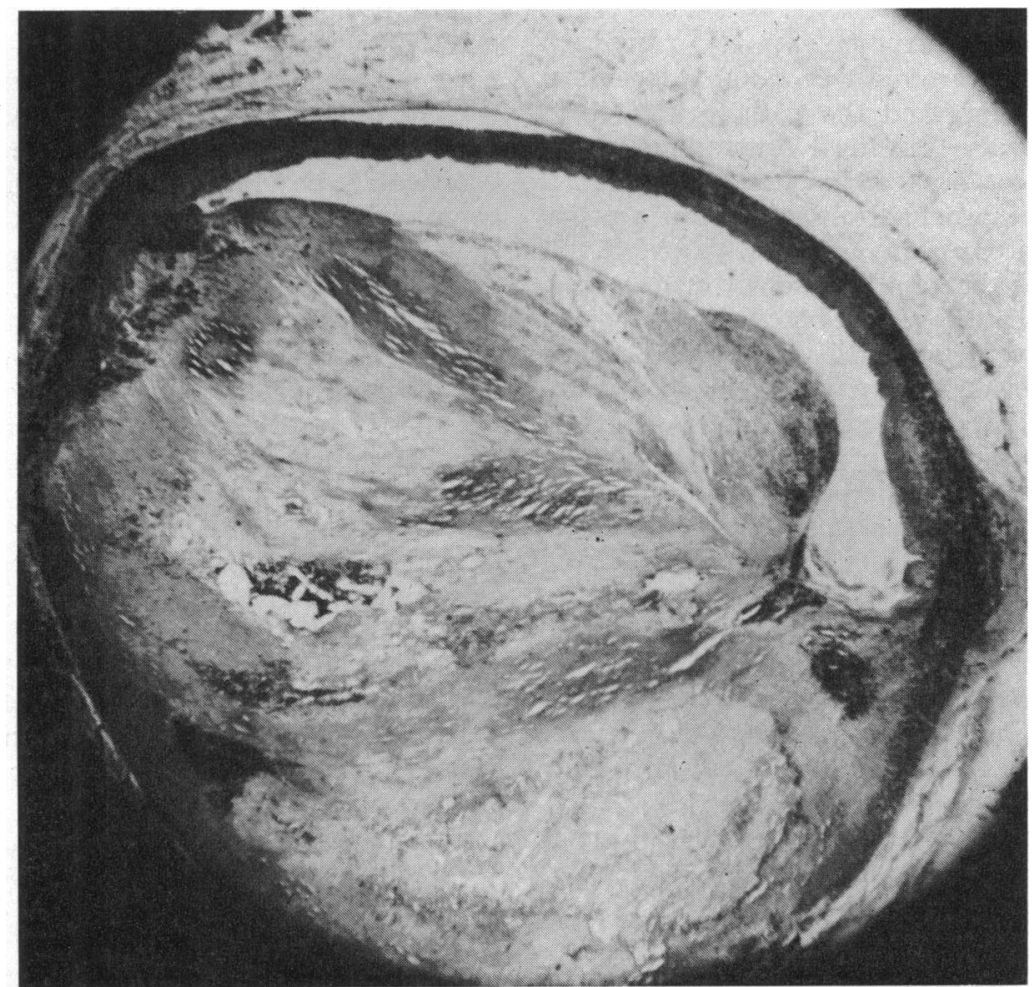

FIG. 6.-Section of anterior descending artery of Case 11 showing stratification of the obstructing material strongly suggesting episodic reduction in coronary flow, which fitted well with the history.

1963) represents recanalization in a thrombus which had formed two years before; it is difficult to conceive that this patient had anything short of a major arterial occlusion, for severe cardiac pain began suddenly, and it was a surprise to find a mere segment of narrowing at the suspected site (anterior descending artery $2-5 \mathrm{~cm}$. from its origin) two years later. If such a process of retraction of thrombus could happen once at a given site, repeated episodes of thrombosis, each followed by some restoration of flow, would also be expected to happen. In Case 11 there was no history to suggest cardiac infarction, but angina of effort became periodically more severe, and on each occasion the patient suffered from rest pain. Coronary arteriography demonstrated occlusion of the right coronary artery as well as severe narrowing in both divisions of the left coronary artery. At necropsy, serial sections of both anterior descending and circumflex arteries showed stratification of "atheroma" within the narrowed segments-well shown in the section of anterior descending artery (Fig. 6). It is reasonable to associate the episodic history of cardiac pain with what was clearly shown to have been an episodic reduction in coronary flow.

In the absence of serial coronary angiographic studies in a large number of patients, it cannot be claimed that progressive or periodical reduction in coronary flow is the only explanation for "decubitus" angina or of angina at rest. Thus in our series of cases of angina, rest pain of unchanging severity was often noted for periods of up to six months and our arteriographic findings suggest that the extent and degree of coronary narrowing is even greater than in patients with effort pain alone.

Place of Coronary Arteriography in Investigation of Patients with Angina Pectoris. It must be emphasized that angina pectoris is a clinical diagnosis and that any evidence of coronary disease obtained from arteriography can only be used to support or confirm, but not to make, a diagnosis. This concept is supported by the inconsistencies revealed when clinical symptoms and disability are correlated with arteriographic findings. Thus there were three patients with severe and typical angina in whom 
coronary arteriography showed little or no disease. Another inconsistency is the well-known fact that occlusive coronary disease at necropsy may not have been associated with recognized cardiac symptoms. Indeed one patient (Case 20) had chest pain with none of the characteristics of angina and a good exercise tolerance, though occlusive coronary disease was found. In this patient we eventually had to assume that he did not experience cardiac pain, and that his symptoms were the result of fear and insecurity in the wake of an episode of cardiac infarction 3 years earlier. Such cases will always raise problems in diagnosis and management, and coronary arteriography may, in the future, be helpful. Our experience is as yet too small and too varied to reach any conclusions on this problem, but analysis of a large number of cases followed over a period of at least 5 years may be more productive (F. M. Sones, 1963, personal communication).

Occasionally it was found that thorough investigation of patients with typical angina led to an improvement in exercise tolerance. One man aged 52 (Case 12) was able to resume work as an engineer with a tolerable degree of effort pain following arteriography which, he rationalized, had resulted in a "cleaning out" of his coronary arteries. Coronary arteriography can hardly be recommended with this in mind, if the same result can be achieved by explanation and reassurance. In a few patients it is helpful to reach a precise diagnosis based on objective evidence provided by coronary arteriography for the unknown may bring greater fear which exaggerates and prolongs anginal pain.

Coronary arteriography will remain essential for the pre-operative assessment of patients if direct coronary surgery is contemplated, but, because of the possibility of further coronary occlusion while awaiting surgery, there should be little delay after the investigation.

The main value of arteriography, however, has been to improve our understanding of coronary disease. Thus correlation of clinical and arteriographic findings has helped to emphasize the value and limitations of the history and the electrocardiogram. Post-mortem studies can demonstrate the presence of collateral channels, but coronary visualization in life is needed to demonstrate their effectiveness.

Diagnostic Value of Coronary Arteriography in Patients with Chest Pain of Uncertain Cause. Coronary arteriography may provide the only clue to the presence or absence of coronary disease in a patient in whom the cause of chest pain is not certain despite a careful history and clinical investigation. While there may be some problems in the interpretation of coronary angiograms, a "severe disease" or a "no disease" assessment cannot be ignored in reaching a final diagnosis, bearing in mind that angina is primarily a clinical diagnosis. Thus the finding of normal, or near normal, coronary arteriograms in 3 patients (Cases 16, 17, and 19) not only provided valuable reassurance to the patients and their medical advisers, but also prompted a closer inquiry into their other possible causes of chest pain. It must be stressed that coronary arteriography is not indicated in every case of chest pain of uncertain cause. This problem is common and often best handled by a confident reassuring approach (pending further observations) and not by raising doubts in the mind of the patient or suggesting further investigation. Hence diagnostic coronary arteriography should be reserved, at present, for those cases where there are special reasons for trying to make a precise diagnosis.

Value of Coronary Arteriography in Investigation of Angina Associated with Valvular Heart Disease. The concept that aortic stenosis necessarily "protects" the coronary arteries is no longer tenable. In the first place necropsy examination has shown that segmental coronary narrowing is frequent in fatal cases of aortic stenosis (Holley et al., 1963; D. Dexter and G. S. Hale, 1962, unpublished observations). Secondly, our experience of coronary arteriography in life in patients with aortic stenosis has demonstrated the importance of performing this investigation, and some even regard it as "mandatory" in the assessment of aortic stenosis prior to operation (Effler et al., 1961). It may be argued that surgery is required in all patients with severe aortic valve disease irrespective of the state of the coronary arteries, but since surgery may involve coronary cannulation and perfusion, prior arteriographic information seems desirable in all cases. Furthermore, there are many patients with aortic stenosis and symptoms who are not clearly suitable for operation because of doubt about the severity of the valve disease. Thus coronary arteriography must be considered to be almost essential in the investigation of some cases of aortic stenosis. From our experience of 5 adults studied by selective arteriography, and a larger number studied by cine-aortography, significant or even dominant coronary disease is suggested by a history of angina beginning abruptly, or one varying greatly in intensity, and slight or no $S-T$ and $T$ wave changes without other evidence of left ventricular hypertrophy on electrocardiograms. Nevertheless angina pectoris in patients with valve disease may not be associated with coronary disease (Stuckey, 
1955) and Case 26 demonstrated that "crescendo" angina may be due to severe aortic stenosis alone, so the pattern of development of symptoms can be misleading. Our experience emphasizes not only the value of coronary arteriography in aortic valve disease, but also that this investigation is indicated here more than in any other group of patients.

\section{SUMMARY}

Selective coronary arteriography has been used over a period of three years to investigate 26 patients with known or suspected ischæmic heart disease.

In 15 patients chronic incapacitating angina was the stimulus for the investigation in the hope of finding cases suitable for endarterectomy. In those with demonstrable proximal occlusion the finding of severe distal disease made the prospects of successful endarterectomy remote. Proximal occlusion was frequent in patients without a history of myocardial infarction and in some patients was thought to be responsible for the onset of angina. The electrocardiogram was sometimes normal despite a long history of severe angina with diffuse coronary narrowing and even proximal occlusion. In 3 patients with classical chronic angina and electrocardiograms showing ischæmia, surprisingly normal coronary arteriograms were obtained.

In 6 patients with chest pain of uncertain origin coronary arteriography gave valuable help in 5, while in one we were still left in doubt. The difficulty in assessment arises from the knowledge that patients with angina and abnormal electrocardiograms have occasionally had little or no evidence of coronary disease by selective arteriography; furthermore it is known that some patients without cardiac symptoms have occlusive coronary disease at necropsy.

In 5 patients with valvular heart disease, and angina, coronary arteriography greatly contributed to their assessment and subsequent management and in these respects appeared to be of greater value than in the other groups of patients.

\section{REFERENCES}

Allbutt, C. (1915). Diseases of the Arteries, Including Angina Pectoris, Vol. II, chapter 6. Macmillan, London.

Allison, P. R. (1962). Thrombo-endarterectomy and its application to coronary artery disease. Brit. med. F., $1,1641$.

Cannon, J. A., Longmire, W. P., and Kattus, A. A. (1959). Considerations of the rationale and technique of coronary endarterectomy for angina pectoris. Surgery, 46, 197.

Crawford, T., Dexter, D., and Teare, R. D. (1961). Coronary-artery pathology in sudden death from myocardial ischæmia. Lancet, 1, 181.

Dexter, D. (1964). The anatomy of coronary disease. In Biological Aspects of Occlusive Vascular Disease, ed. D. G. Chalmers, and G. A. Gresham, p. 301. University Press, Cambridge.

Duguid, J. B., and Robertson, W. B. (1957). Mechanical factors in atherosclerosis. Lancet, 1, 1205.

Effler, D. B., Groves, L. K., Sones, F. M., Jr., and Shirey, E. K. (1961). Calcific aortic stenosis-an effective surgical treatment. 34th Scientific Session, American Heart Association. Circulation, 24, 924.

Evans, W. (1959). Faults in the diagnosis and management of cardiac pain. Brit. med. F., 1, 249.

Hale, G., and Jefferson, K. (1963). Technique and interpretation of selective coronary arteriography in man. Brit. Heart f., 25, 644.

Hand, R. A., and Chandler, A. B. (1962). Atherosclerotic metamorphosis of autologous pulmonary thromboemboli in the rabbit. Amer. F. Path., 40, 469.

Herrick, J. B. (1912). Clinical features of sudden obstruction of the coronary arteries. f. Amer. med. Ass., 59, 2015.

Holley, K. E., Bahn, R. C., McGoon, D. C., and Mankin, H. T. (1963). Calcific embolization associated with valvotomy for calcific aortic stenosis. Circulation, 28, 175.

Longmire, W. P., Cannon, J. A., and Kattus, A. A. (1959). The surgical treatment of angina pectoris. Arch. intern. Med., 104, 886.

Michell, G., and Jefferson, K. (1962). Angiography of the coronary circulation in living dogs using timed diastolic injections. Brit. Heart F., 24, 11.

Schlesinger, M. J., and Zoll, P. M. (1941). Incidence and localization of coronary artery occlusions. Arch. Path., $32,178$.

Shipley, R. E., and Gregg, D. E. (1944). The effect of external constriction of a blood vessel on blood flow. Amer. f. Physiol., 141, 289.

Sloman, G., and Jefferson, K. (1960). Cine-angiography of the coronary circulation in living dogs. Brit. Heart $\mathcal{f}$., $22,54$.

Sones, F. M. (1960). Cine-cardioangiography. In Clinical Cardiopulmonary Physiology, 2nd edn., ed. B. L. Gordon, p. 136. Grune and Stratton, New York.

Stuckey, D. (1955). Cardiac pain in association with mitral stenosis and congenital heart disease. Brit. Heart $\mathcal{F}$., 17, 397.

Swedlund, H. A., Achor, R. W. P., and Edwards, J. E. (1962). A clinicopathologic study on the feasibility of direct surgical treatment of occlusive coronary arterial disease. Circulation, 25, 292.

Szilagyi, D. E., McDonald, R. T., and France, L. C. (1958). The applicability of angioplastic procedures in coronary atherosclerosis. Ann. Surg., 148, 447.

Thal, A. P., Richards, L. S., Greenspan, R., and Murray, M. J. (1958). Arteriographic studies of the coronary arteries in ischæmic heart disease. F. Amer. med. Ass., 168, 2104.

Willius, F. A., and Keys, T. E. (1941). Cardiac Classics. Mosby, St. Louis.

Wood, P. (1961). Acute and subacute coronary insufficiency. Brit. med. F., 1, 1779.

Zoll, P. M., Wessler, S., and Blumgart, H. L. (1951). Angina pectoris. Amer. F. Med., 11, 331. 